\title{
The possible therapeutic Effect of Mesenchymal Stem Cells and Vitamin E on Experimentally Induced Ulcerative Colitis in Adult Male Albino Rats: Histological and immunohistochemical study
}

\author{
Omayma K. Helal ${ }^{\text {a }}$, Hala G. Metwaly ${ }^{\text {, }}$, Maha M. Abo Gazia ${ }^{\mathrm{c}}$, Rania El Desoki ${ }^{\mathrm{a}}$, Naira El \\ Ashmouny ${ }^{\mathrm{c}}$
}

${ }^{\mathrm{a}}$ Department of Histology and Cell Biology, faculty of medicine, Benha University, Egypt. b Department of Clinical Pathology, Faculty of Medicine, Cairo University, Egypt. c Department of Histology and Cell Biology, Faculty of Medicine- Kafr El Sheikh University. Egypt.

Correspondence to: Naira El Ashmouny, Department of Histology and Cell Biology, Faculty of Medicine- Kafr El Sheikh University. Egypt.

Email:

naiera.elashmony@yahoo.com

Received: 15 February 2020

Accepted: 12 April 2021

\begin{abstract}
Background: Ulcerative colitis (UC) is one of the inflammatory bowel diseases (IBD) that results in recurrent inflammation and ulcers of the colon and rectum. Aim: The aim of the study was to explore the possible therapeutic effect of bone marrow-derived mesenchymal stem cells (BM-MSCs) and vitamin E on experimentally induced UC in rats. Materials and methods: Sixty rats were divided into five main groups: group I (control group); group II (UC) consisted of 10 rats that received a single intrarectal injection of $2 \mathrm{ml}$ of $3 \%$ acetic acid; group III (10 rats) consisted of rats that received vitamin $E$ three times in a week orally after induction of ulcerative colitis; group IV consisted of 10 rats that received a single injection of BM-MSCs after induction of ulcerative colitis ; and group $\mathrm{V}$ comprised 10 rats that received both vitamin E orally and BM-MSCs after induction of colitis. Colonic samples were examined using light and fluorescent microscopy. Results: Group II showed ulceration, loss of surface columnar epithelium, disturbed crypts architecture with few goblet cells and many cellular infiltrations. Group III showed a picture that was nearly similar
\end{abstract} to UC group. Group IV showed improvement in colitis. Group V showed a histological picture that was nearly similar to the control group. Conclusions: BM-MSCs represent future therapeutic hopes for chronic intestinal inflammatory states through their regenerative and anti-inflammatory effects. The combination of vitamin E and BM-MSCs was more effective and produced an additive effect than using bone marrow derived MSCs alone.

Keywords: Ulcerative colitis, Acetic acid, MSCs, PKH26, Rat colon. 


\section{Introduction}

Ulcerative colitis (UC) is one form of inflammatory bowel disease (IBD), characterized by being a chronic relapsing non-transmural inflammatory disease that is restricted to the colon resulting in colonic mucosal inflammation, ulceration, edema, and bleeding (1). It is a multifactorial intestinal disorder with high incidence and characterized by a pattern of mucosal inflammation that starts in the rectum and proceeds continuously from distal to proximal colon (2). UC is most commonly presented with abdominal pain, bloody diarrhea and mucus per rectum. According to numerous studies, UC is associated with genetic and environmental factors, immunological disorders, and the production of reactive oxygen species (ROS). However, the pathogenesis of IBD remains poorly understood (4). The colitis mouse model chemically induced by acetic acid has shown symptoms similar to UC in humans, including histopathological appearance, body weight loss, bloody diarrhea, and shortening of the colon (5). Several major causative factors in the initiation of human colitis such as enhanced vasopermeability, prolonged neutrophils infiltration and increased production of inflammatory mediators are involved in the induction of this animal acetic acid model (6).
Although many treatments have been developed for patients with UC, there is still no widely accepted effective treatment for UC. Therefore, newly emerging therapies, especially mesenchymal stem cell (MSC) therapy, are being investigated as a treatment strategy for UC (7).

MSCs can be isolated from various cell types, including adipose tissue, dental pulp, peripheral blood, placenta, and umbilical cord. Besides being multipotent cells characterized by the ability to differentiate into varying cell lines and to exert selfrenewal, they have the capability to secrete cytokines or chemokines to exert their different functions, as immunomodulatory, and anti-inflammatory effects in the gastrointestinal tract (8). Of all the adult stem cell types, MSCs are of considerable interest as they have no ethical concerns when compared with embryonic stem cells. These unique biological properties of cellular therapy have made it attractive for inflammatory and autoimmune diseases as the treatment must be multifocal and include the ability to dampen inflammation, minimize opportunistic infection and stimulate repair (9). Although MSCs are a good candidate for promising cell-based therapy against tissue injury, they are subject to limitations in replicative life span which is mainly 
attributed to telomere shortening. MSCs are very sensitive to oxygen concentration and ROS accumulation in ischemic tissues or in culture, leading to reduced growth rate and capacity, as well as decreased potential for differentiation. Therefore, strategies for enhancing stem cell survival, proliferation, and differentiation have become one of the important topics. The application of an adjuvant antioxidant drug is a promising method to support stem cell therapy $(10,11)$

Vitamin $\mathrm{E}$ is a natural antioxidant which quench ROS, therefore may prevent the increase of free radicals produced by oxidative damage of lipids and lipoproteins in cellular components and tissues (12). ROS can attack double bonds in polyunsaturated fatty acids in cellular components and thus induce lipid peroxidation, which may result in more oxidative damage. Increasing attention has been focused on the role of ROS produced by activated neutrophils during IBD (13). ROS molecules can highly attack cell components, causing further injury in colonic tissue (14)

This study aimed to assess the possible therapeutic effect of BM-MSCs and vitamin E on experimentally induced UC in rats.

\section{Materials and methods:}

\section{Reagents}

Acetic acid was obtained by El-Gomhoria Company for Trading Pharmaceuticals Chemicals and Medical Appliances, Egypt. Vitamin E was produced by PHARCO corporation (Egypt) in the form of soft gelatin capsules. capsule contains $400 \mathrm{mg}$ vitamin E. Each capsule was emptied and dissolved in 16 $\mathrm{ml}$ of sunflower oil and were given three times in a week in a dose (100 mg/kg/day) orally through a gastric tube (15).

PKH26 labelled BM-MSCs were obtained from the Biochemistry Department, Faculty of Medicine, Kasr El-Eini Hospital. The BMSCs were injected intravenously into the tail vein of each rat at a single dose of $5 \times 105$ cells $/ 150 \mu \mathrm{l}$ in Phosphate Buffered Saline (PBS) (7).

\section{Animals:}

Sixty healthy adult male albino rats weighing from 150 to $200 \mathrm{~g}$ each. Animal care was provided by Laboratory Animal House of Kasr El-Eini Hospital, where rats were fed a balanced diet and had free access to water. The study was approved by the Ethical scientific committee of Benha University and took place on November 2017 for 8 days. 
All animal procedures were performed according to approved protocols and in accordance with the recommendations for the proper care and use of laboratory animals. They were kept under observation for 1 week before the beginning of the experiment to acclimatize to their environment.

Type of the study is Case / Control study.

\section{Experimental procedure:}

The animals were divided into five main groups: (1) Group I (the control group): 20 rats were subdivided equally into four groups:

(a) Subgroup A: the rats in this group were kept without treatment for the same periods as experimental animals.

(b) Subgroup B: the rats in this group received once intra-rectal injection of $2 \mathrm{ml}$ physiologic saline.

(c) Subgroup C: the animals in this group received $1 \mathrm{ml}$ sunflower oil (the dissolving vehicle for vitamin $E$ ) three times in a week through gastric gavage.

(d) Subgroup D: the animals in this group received a single injection of phosphate buffer saline (PBS) intravenously (i.v.) via tail vein. The rats were sacrificed on 8th day of experiment.

(2) Group II (UC group): 10 rats received a single intra-rectal injection of $2 \mathrm{ml}$ of $3 \%$ acetic acid and sacrificed on 8th day of experiment.

(3) Group III (vitamin E group): 10 rats received vitamin $\mathrm{E}$ orally after a single intrarectal injection of $2 \mathrm{ml}$ of $3 \%$ acetic acid for induction of ulcerative colitis. Vitamin E was given three times in a week in a dose (100 $\mathrm{mg} / \mathrm{kg}$ body weight) by gastric gavage and rats were sacrificed on 8th day of experiment.

(4) Group IV (BM-MSC group): 10 rats received a single injection of (BM-MSCs) $5 \times 105$ cells $/ 150 \mu \mathrm{l}$ in Phosphate buffered saline via tail vein after induction of UC, then 2 rats were sacrificed after 3 days of stem cell injection for detection of homing and the remaining 8 rats were sacrificed on 8 th day of experiment

(5) Group V (vitamin E \& BM-MSC group): 10 rats received both vitamin $\mathrm{E}$ orally (in a dose $100 \mathrm{mg} / \mathrm{kg}$ body weight) three times in a week and BM-MSCs $5 \times 105$ cells $/ 150 \mu \mathrm{l}$ in Phosphate buffered saline via tail vein 24 hours after induction of UC, then sacrificed on 8th day of experiment .

\section{Induction of ulcerative colitis}

Ulcerative colitis was induced in rats by slightly anaesthetizing rats with ether inhalation following 24 hours fasting, and then $6 \mathrm{~cm}$ of soft pediatric catheter size $6 \mathrm{~F}$ was lubricated with gel then inserted into the anus and the tip was advanced to $8 \mathrm{~cm}$ 
proximal to the anus verge. $2 \mathrm{ml}$ of acetic acid $(3 \% \mathrm{v} / \mathrm{v}$ in $0.9 \%$ saline) was instilled into the colon through the catheter; each rat remained suspended in a head down vertical position for one minute to prevent leakage of the intracolonic instillation $(16,17)$.

\section{Isolation of BM-derived MSCs from rats:}

Bone marrow was harvested by flushing the tibiae and femurs of five 6 weeks old male white albino rats with Dulbecco's modified Eagle's medium (DMEM, GIBCO/BRL) supplemented with $10 \%$ fetal bovine medium (GIBCO/ BRL). Nucleated cells were isolated with a density gradient [Ficoll/Paque (Pharmacia)] and resuspended in complete culture medium supplemented with $1 \%$ penicillin-streptomycin (GIBCO/BRL). Cells were incubated at $37^{\circ} \mathrm{C}$ in $5 \%$ humidified $\mathrm{Co} 2$ for 12-14 days as primary culture or upon formation of large colonies. When large colonies developed (80-90\% confluence), cultures were washed twice with phosphate buffer saline (PBS) and cells were trypsinized with $0.25 \%$ trypsin in $1 \mathrm{mM}$ EDTA (GIBCO/BRL) for 5 minutes at $37^{\circ} \mathrm{C}$. After centrifugation (at $2400 \mathrm{rpm}$ for 20 minutes), cells were resuspended with serumsupplemented medium and incubated in 50 cm 2 culture flask Falcon). The resulting cultures were referred to as first-passage cultures (18). BM-MSCs in culture were characterized by their adhesiveness and fusiform shape attached to the floor of flask. (19).

\section{Labeling of stem cells with PKH26} dye:

MSCs cells were harvested during the 4th passage and were labeled with PKH26 fluorescent linker dye. PKH26 is a red fluorochrome, has excitation $(551 \mathrm{~nm})$ and emission $(567 \mathrm{~nm})$. The linkers are physiologically stable and show little to no toxic side-effects on cell systems. Labeled cells retain both biological and proliferating activity, and are ideal for in vitro cell labeling, in vitro proliferation studies and long term, in vivo cell tracking (20).

\section{Histological study:}

The rats were anesthetized with ether and the abdominal walls was opened exposing the viscera. The abdominal wall was retracted, and the colon was removed rapidly (21). The colon was dissected and the distal $3 \mathrm{~cm}$ of the colon of each rat was taken immediately and divided into two specimens, one was fixed in $10 \%$ formol saline solution and was processed to get paraffin sections of 5 microns thickness, and mounted and subjected to the following stains: H\&E (22), periodic acid Schiff reaction (PAS) (23), immunohistochemical staining for: 
1- Proliferating cellular nuclear antigen (PCNA) (catalogue number: MS106P) whose level correlates directly with rates of cellular proliferation and DNA synthesis (24). The primary antibody was monoclonal antibody (Lab. Vision Corporation Laboratories) diluted by $1: 25$. The sections were examined with light microscope and Negative controls were prepared by omitting the primary antibody. Positive tissue control was performed by applying the previous technique in the same way on human tonsil specimen (www. novusbio.com).

2- Cyclooxygenase 2 (COX-2) (catalogue number: MAD-000335Q-3) which associated with the mediation of inflammation (25). The primary antibody was obtained from Master Diagnostica diluted by 1:50. Positive tissue control was performed by applying the previous technique in the same way on human lung cancer specimen (www.ptglab.com).

3- Factor VIII (catalogue number: MS-722RQ) (26) which is a marker to identify endothelial cells. The primary antibody was obtained from Lab. Vision Corporation Laboratories diluted by 1:50. Positive tissue control was performed by applying the previous technique in the same way on human Tonsil specimen (www.mybiosource.com).

\begin{tabular}{|c|c|c|}
\hline 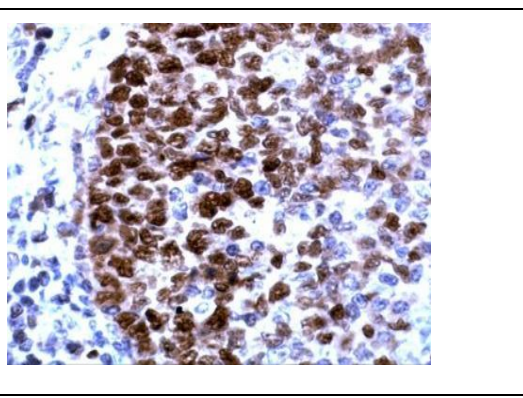 & 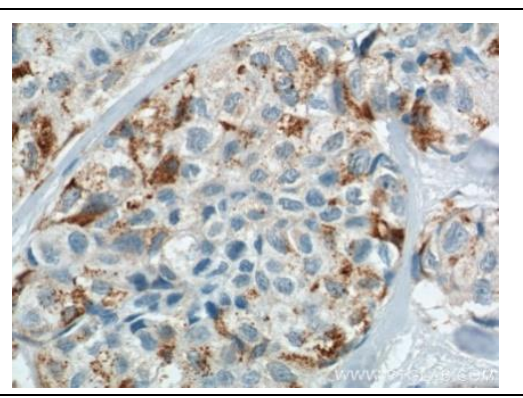 & 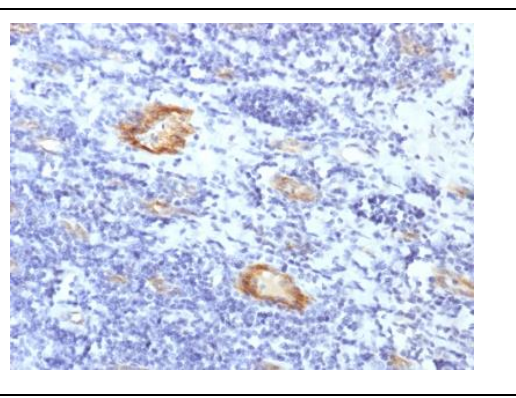 \\
\hline $\begin{array}{l}\text { positive control section from } \\
\text { human tonsil showing +ve } \\
\text { immunostaining for PCNA }\end{array}$ & $\begin{array}{l}\text { positive control section from } \\
\text { human lung cancer showing +ve } \\
\text { immunostaining for COX-2 } \\
\text { (COX- } \\
2 \text { immunostaining } \times 400 \text { ) }\end{array}$ & 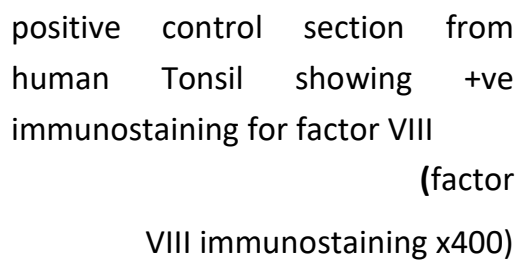 \\
\hline
\end{tabular}

\section{Morphometric study:}

Using Leica Qwin 500C image analysis, assessment of the mean number of goblet cells in PAS stained sections, mean number of positive immunoreactive PCNA cells, mean area\% of positive immunoreactivity for
COX2 were performed. The measurements were done in 10 nonoverlapping high power fields (HPF) in control and experimental groups. The mean vascular density for factor 
VIII positive endothelial cells was performed by selecting three hot spots for each group.

\section{Statistical analysis}

Quantitative data were summarized as means and standard deviations and compared using one-way analysis-of-variance (ANOVA). pvalues $<0.05$ was considered statistically significant. Calculations were made on SPSS software (27).

\section{Results}

\section{Detection of PKH26 labeled mesenchymal} stem cells by fluorescent microscope in unstained colonic sections:

Detection of the BM-MSCs homing in colon after its labelling with PKH26 dye was done by fluorescent microscope in department of histology and cell biology, faculty of medicine, Tanta university. Two rats from BM-MSC group were sacrificed after 3days of BM-MSC injection. The red fluorescence of PKH26 was detected to ensure homing and to trace the injected BM-MSCs in the colon tissue (fig. 1,2).

\section{Hematoxylin and Eosin (H\&E) stained sections:}

All control subgroups showed the same histological picture. They revealed intact mucosal architecture. This intact mucosa exhibited regularly arranged, closely related crypts. Simple columnar cells and many goblet cells lined the mucosa and the crypts. Between the crypts, in the lamina propria, minute blood capillaries were seen (Fig. 3). UC group revealed a focal area of loss of surface columnar epithelial lining and disturbed crypt architecture with depletion of goblet cells. Inflammatory cellular infiltration was observed replacing the crypts with dilated congested blood capillaries with extravasated RBCs. (Fig. 4). Vitamin E group revealed loss of surface columnar epithelial lining. The mucosa contained congested blood vessels with extravasated RBCs. Cellular infiltration was observed in replacing the crypts (Fig. 5). BM-MSC group showed apparently normal intact surface columnar cells. Some mucosal crypts were apparently intact and were spaced by little inflammatory cell infiltration (Fig. 6). BM-MSC and vitamin E group colon sections showed apparently intact mucosal lining and crypts. The crypts were lined mainly by goblet cells and were spaced by apparently normal looking lamina propria (Fig. 7).

\section{Periodic Acid Schiff Reaction (PAS) stained sections:}

The control group showed colonic mucosa with apparent strong PAS +ve reaction indicating the mucin secreting goblet cells lining the crypts (Fig.8). UC Group showed apparent weakly PAS +ve stained mucin secreting goblet cells (Fig.9). Group vitamin E showed apparent weakly positive PAS 
stained goblet cells (Fig.10). BM-MSC group showed variable degrees of PAS reaction. Examination of PAS stained sections of the colon showed increase in mucin secreting cells with apparent increase in the intensity of PAS +ve reaction (Fig. 11). BM-MSC and vitamin E group colon sections showed apparent increase in mucin secreting cells that lined the surface mucosa and apparent strong PAS +ve reaction, similar to control group (Fig. 12).

\section{PCNA immunohistochemical results}

Control group (group I) showed positive brownish, nuclear PCNA immune reaction distributed in lower part of the crypts. (fig.13). Both UC group (group II) (fig.14) and vitamin E group (group III) (fig.15) showed an apparent decrease in PCNA immunoreactive cells appeared in crypts. On the other hand, BM-MSC group (group IV) showed apparent increase in PCNA immune reaction (fig.16) as well as BM-MSC and vitamin E group (group V) (fig. 17).

\section{COX-2 immunohistochemical results:}

COX-2 immunohistochemistry exhibited apparent weak expression in Control group (Group I) (fig.18), while both UC group (Group II) (fig.19) and vitamin E group (Group III) showed an apparent strong positive cytoplasmic reaction to $\mathrm{COX}-2$ (fig.20). However, examination of BM-MSC group (Group IV) showed apparent decrease in COX-2 expression (fig.21). on the other hand, BM-MSC and vitamin E group: (Group V) revealed an apparent weak immune reaction to $\mathrm{COX}-2$ (fig.22).

\section{Factor VIII immunohistochemical results:}

Examination of control group (group I) showed few positive brownish immunostained blood vessels to factor VIII, which is an endothelial cell marker (fig.23). on the other hand, examination of both colitis group (group II) (fig.24) and vitamin E group (group III( )fig.25) revealed an increase in number of blood vessels with +ve immunostaining to factor VIII in the endothelium of the capillaries. However, MSC group (group IV) (fig.26) and MSC and vitamin E group (group V) (fig.27) showed a few +ve brownish immunostained blood vessels to factor VIII.

\section{Morphometric results:}

The statistical analysis was carried out using one- way ANOVA analysis of variance for comparison between the different groups, using SPSS (version 16; SPSS Inc., Chicago, Illinois, USA). P values of 0.05 or less were accepted as statistically significant.

The mean number of goblet cells in PAS stained sections, mean number of positive immunoreactive cells for PCNA, mean area\% of positive immunoreactivity for 
COX2, and mean vascular density for factor VIII positive endothelial cells for all groups is presented in Tables 1, 2, 3 and 4 and in Histograms 1, 2, 3 and 4. Statistical analysis by ANOVA test demonstrated a significant increase in mean number of both PASpositive goblet cells and PCNA immunoreactive cells, a significant decrease in both mean area\% of positive immunoreactivity for COX2 expression and in number of blood vessels with +ve immunostaining to factor VIII $(P<0.05)$ in groups IV, and V compared with group II, but these parameters were nonsignificant in group III.

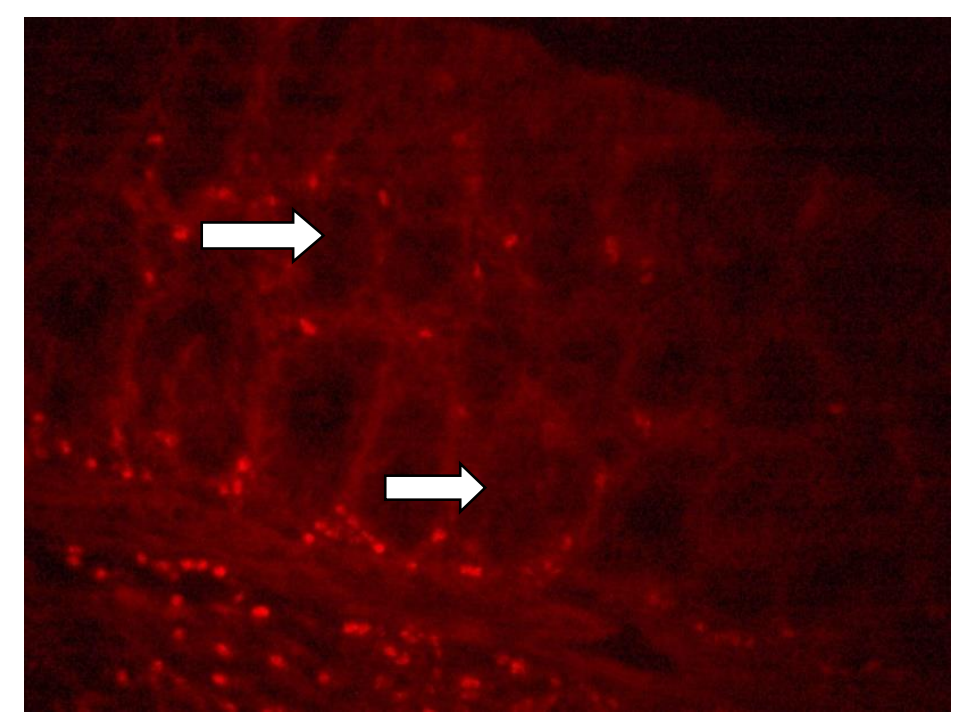

Fig. (1): Homing of injected PKH26 labeled BM-MSCs (arrows) in rat colon tissue between and at the base of the crypts. (PKH26 labeled BM-MSCs immunofluorescence $x$ 400)

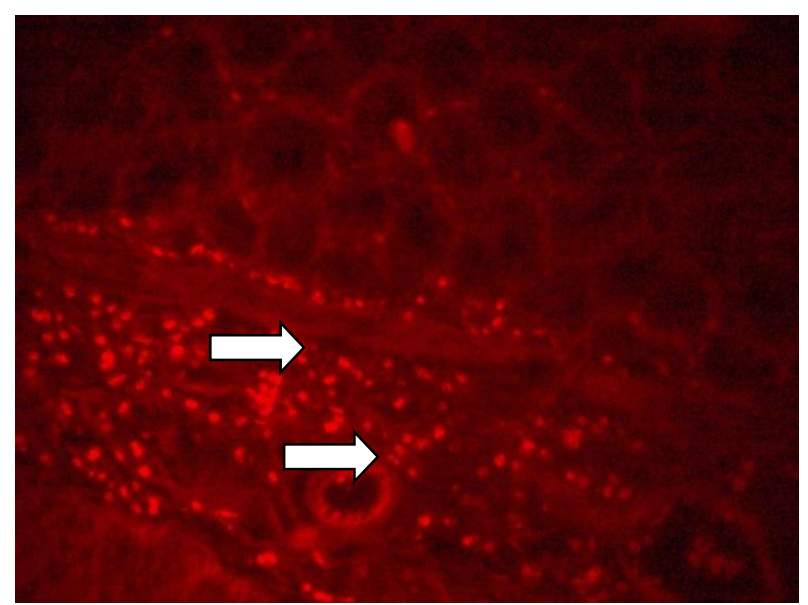

Fig. (2): Homing of injected PKH26 labeled BM-MSCs (arrows) in rat colon within and around the blood vessel in the submucosa were noted. (PKH26 labeled BM-MSCs immunofluorescence x 400) 
Benha medical journal vol. 38, issue 1, 2021

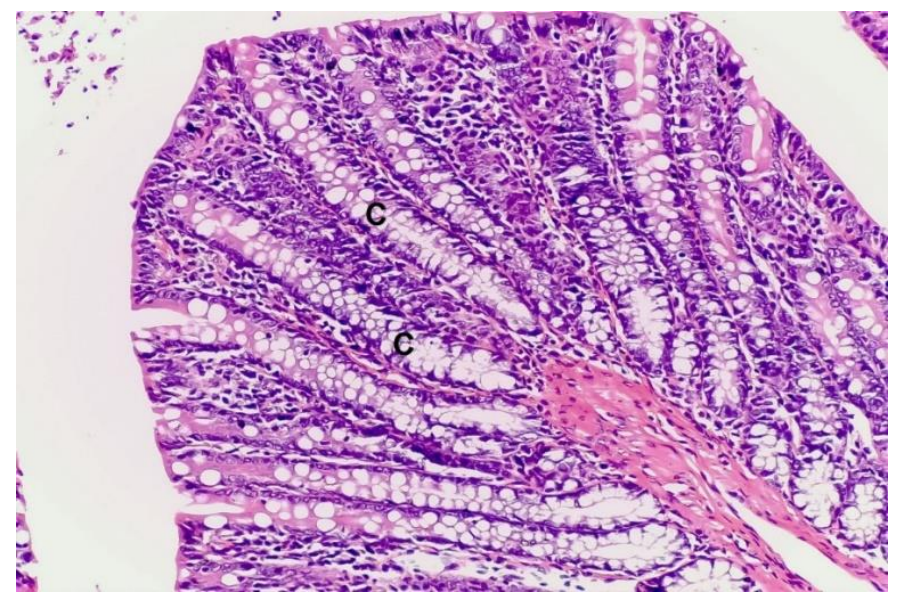

Fig. (3): A photomicrograph of a section in the rat colon of control group (group I) showing intact mucosal architecture of the colon with regularly arranged closely related crypts (C).(Hx \& E., x 200)

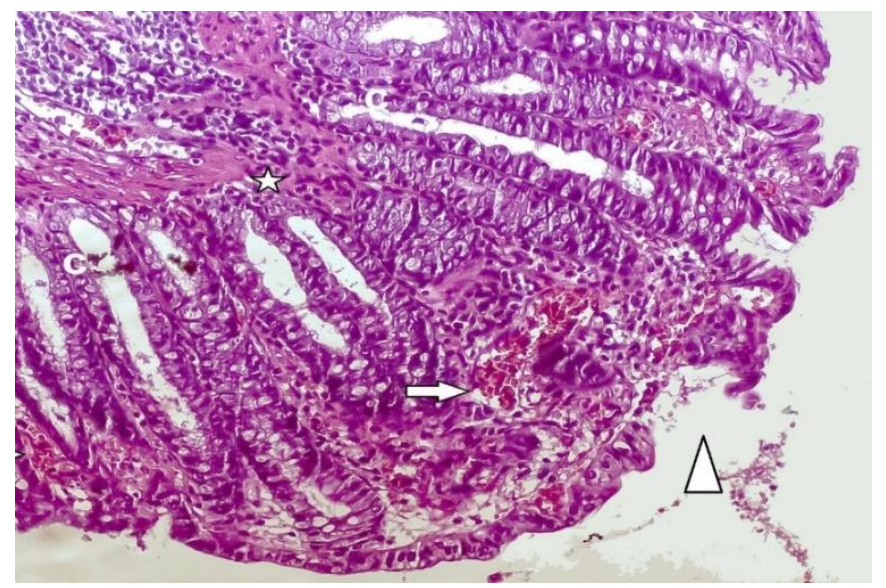

Fig. (4): A photomicrograph of a section in the rat colon of colitis group (group II) demonstrating an area of loss of surface epithelial lining (arrowhead). Cellular infiltration (star) in between crypts (C) and in mucosa and dilated congested blood capillaries (arrows) with extravasated RBCs were also seen. (Hx \& E., x 200)

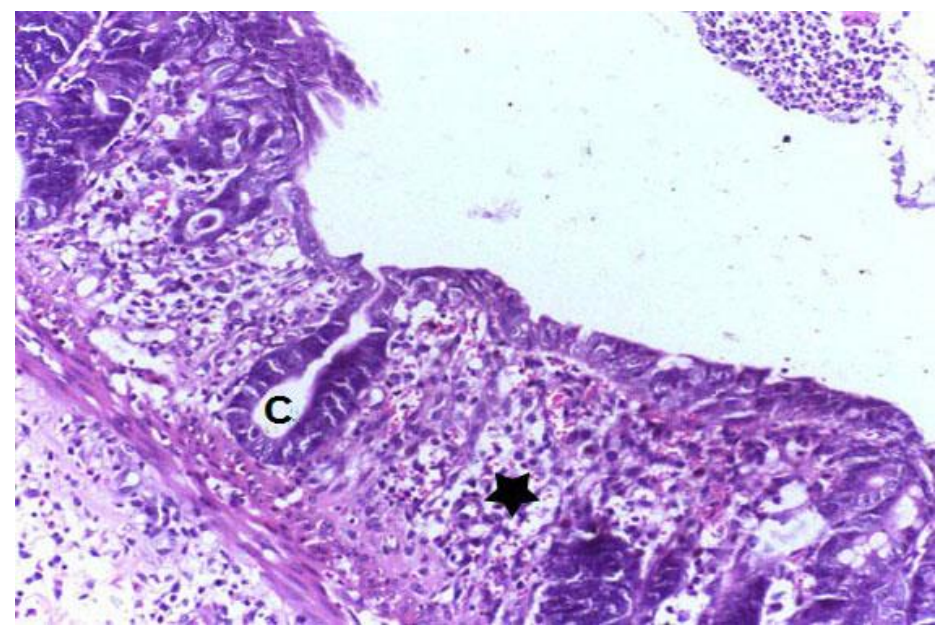

Fig. (5): A photomicrograph of a section in the rat colon of vitamin E group (group III) illustrating cellular infiltration (star) replacing the crypts $(\mathrm{C}) .(\mathrm{Hx} \& \mathrm{E} ., 200)$ 


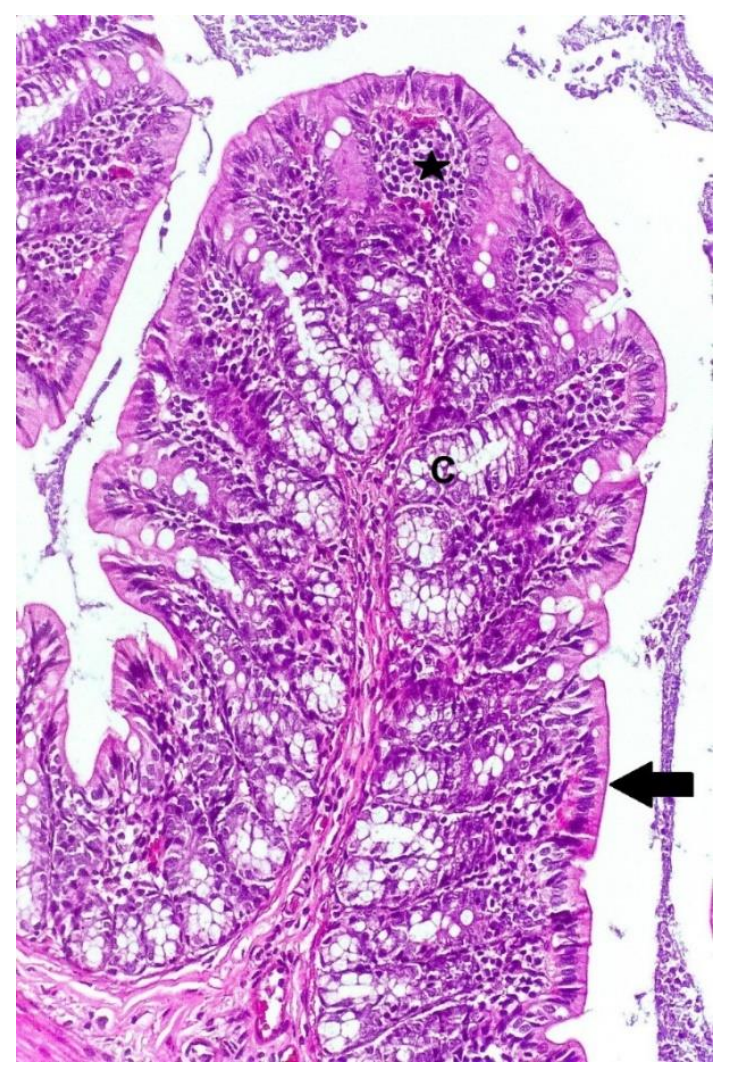

Fig. (6): A photomicrograph of a section in the rat colon of MSC group (group IV) demonstrating apparently intact mucosal architecture with regular crypts (C) spaced by cellular infiltration (star). Mucosa is lined by a continuous layer of epithelium (arrow).(Hx \& E., x 200)

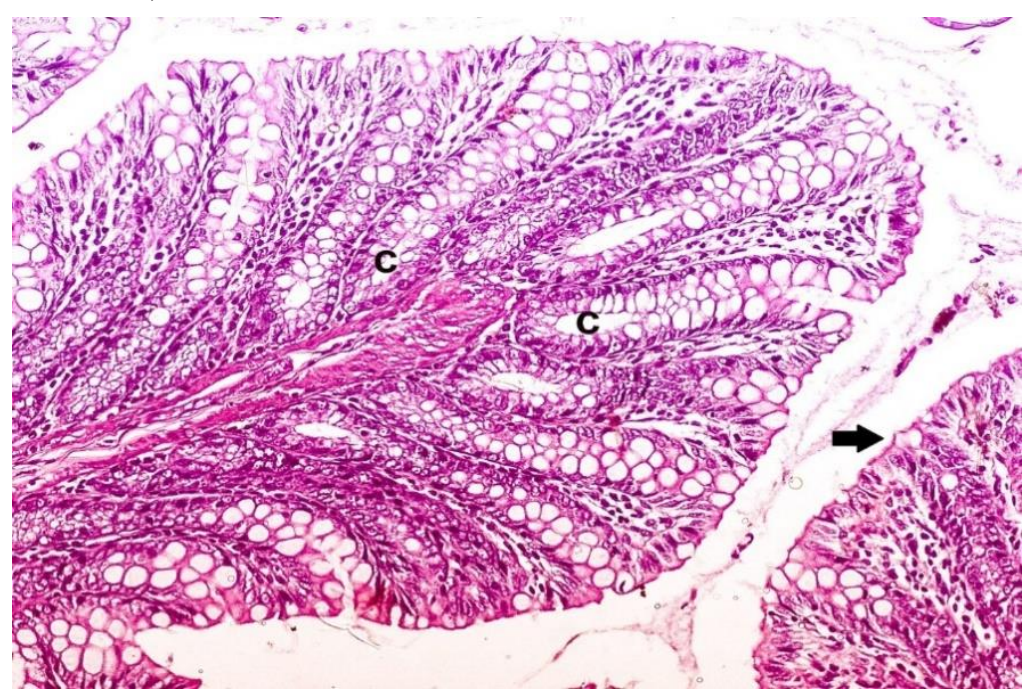

Fig. (7): A photomicrograph of a section in the rat colon of MSC and vitamin E group (group V) illustrating continuous surface columnar epithelium with goblet cells (arrow) and regularly arranged colonic crypts (C).(Hx \& E., x 200) 
Benha medical journal vol. 38, issue 1, 2021

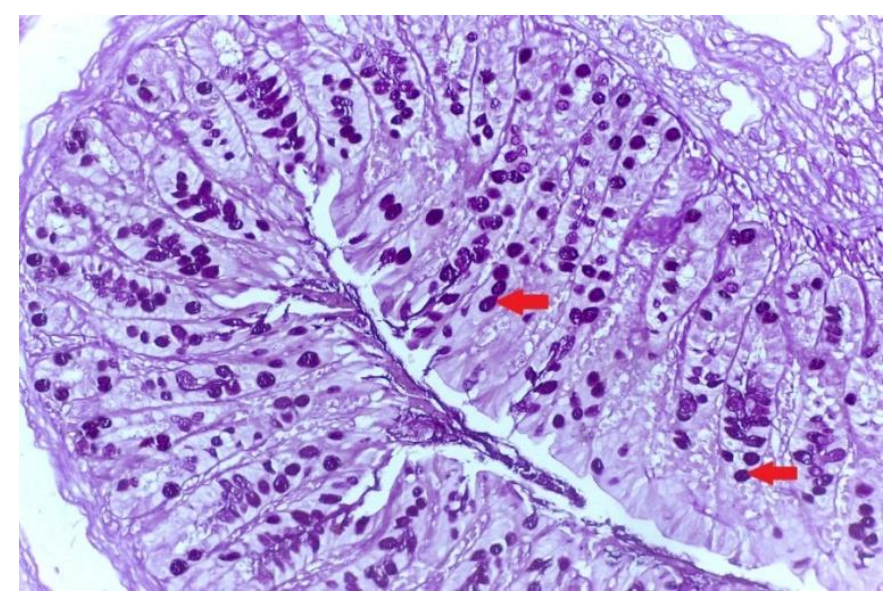

Fig. (8): A Photomicrograph of PAS stained section of rat colonic tissues of control group (group I) showing goblet cells with strong +ve PAS reaction (arrow).(PAS x 200)

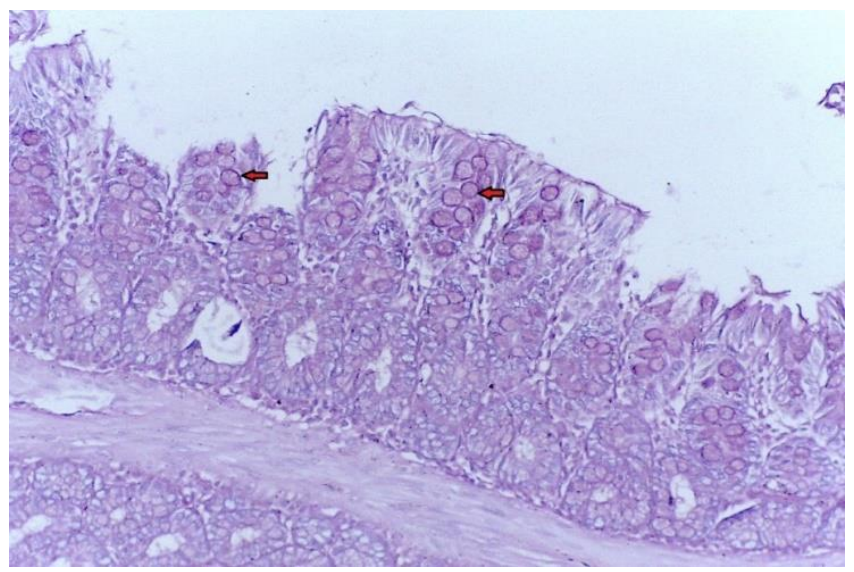

Fig. (9): A Photomicrograph of PAS stained sections of rat colonic tissues of colitis group (group II) showing apparent weakly positive PAS stained goblet cells (arrow).(PAS x 200)

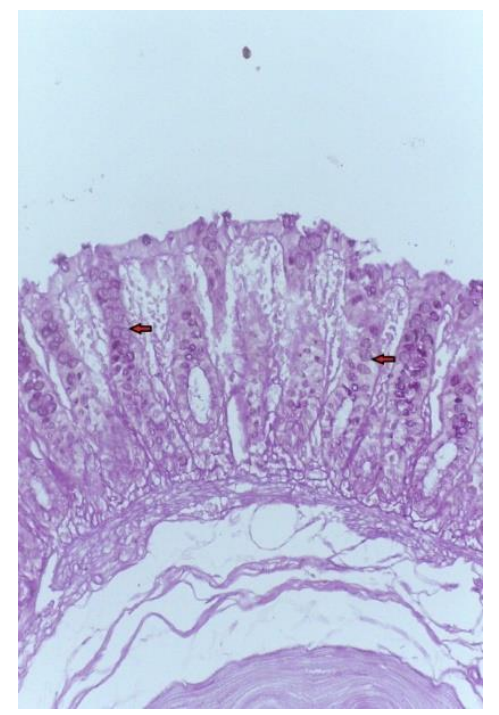

Fig. (10): A Photomicrograph of PAS stained sections of rat colonic tissues of vitamin E group (group III) illustrate apparent weakly positive PAS stained goblet cells (arrow).(PAS x 200) 


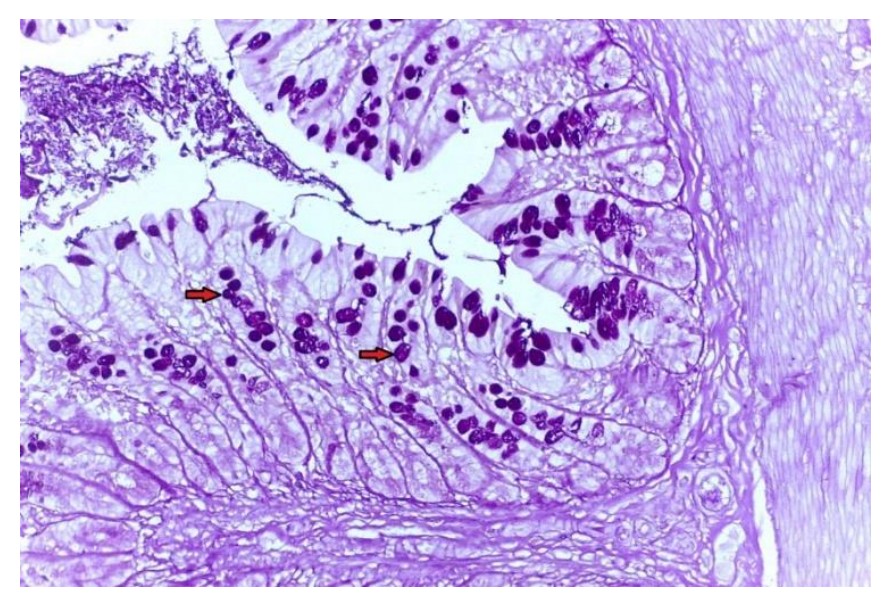

Fig. (11): A Photomicrograph of PAS stained sections of rat colonic tissues of MSC group (group IV) revealed apparent increase in mucin secreting cells that lined the surface mucosa and the crypts with apparent increase in the intensity of PAS +ve reaction (arrow).(PAS x 200)

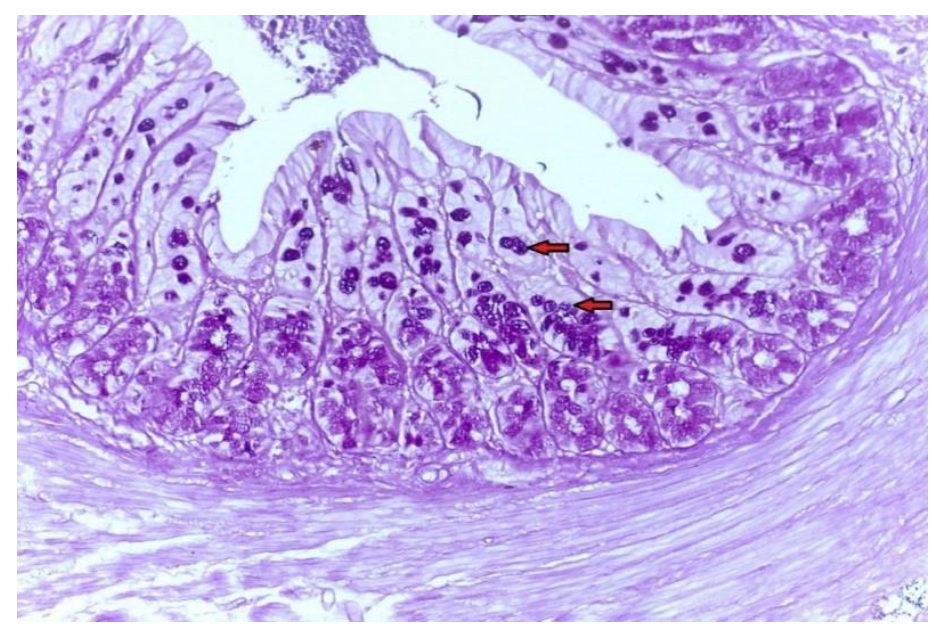

Fig. (12): A Photomicrograph of PAS stained sections of rat colonic tissues of MSC and vitamin E group (group V) revealed apparent increase in mucin secreting cells that lined the surface mucosa and the crypts with apparent increase in the intensity of PAS +ve reaction (arrow). (PAS x 200)

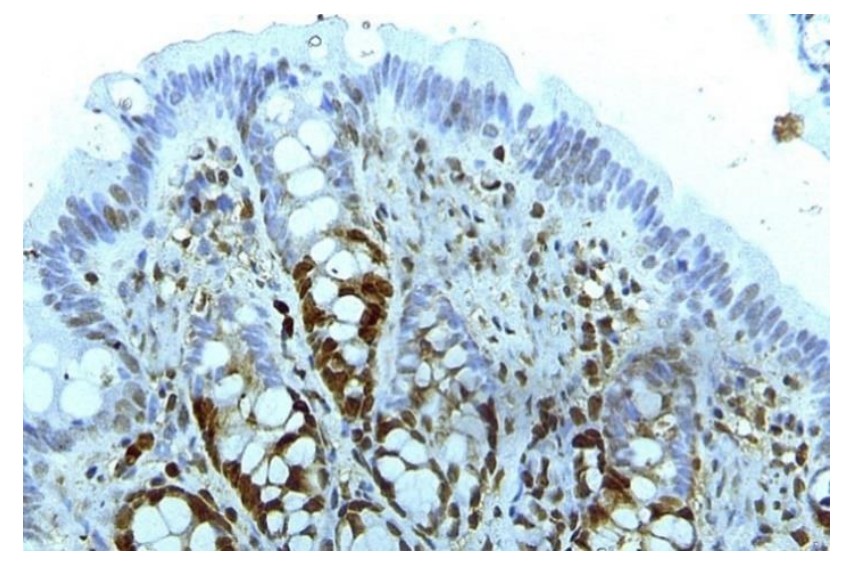

Fig. (13): A Photomicrograph of a section in the rat colon of control group (group I) showing positive brownish, nuclear PCNA immune reaction distributed in lower part of the crypts (arrow). (PCNA immunostaining x 400) 
Benha medical journal vol. 38, issue 1, 2021

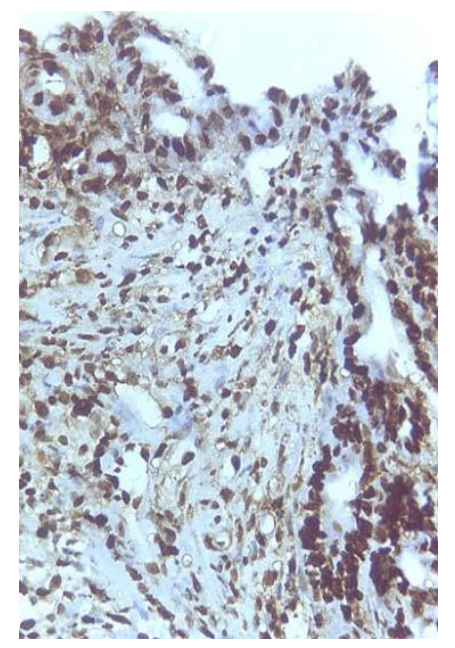

Fig. (14): A Photomicrograph of a section in the rat colon of colitis group (group II) showing apparent decrease in the number of PCNA immunoreactive cells in widespread areas. (PCNA immunostaining x 400)

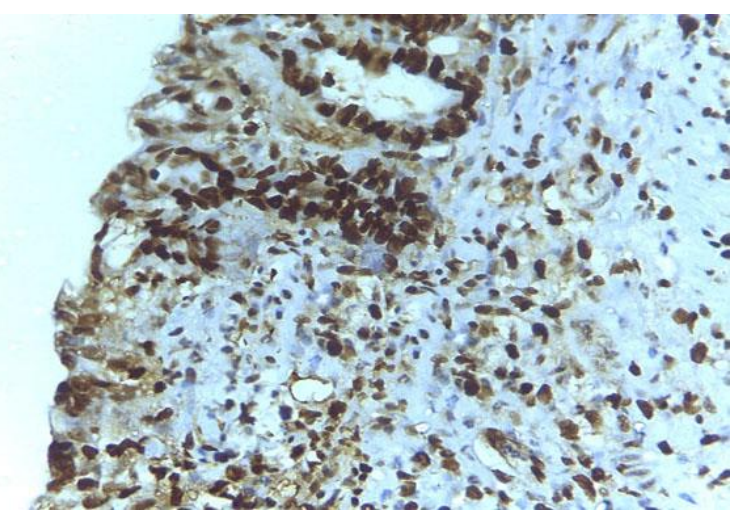

Fig. (15): A Photomicrograph of a section in the rat colon of vitamin E group (group III) showing apparent decrease in the number of PCNA immunoreactive cells in colon sections. (PCNA immunostaining x 400)

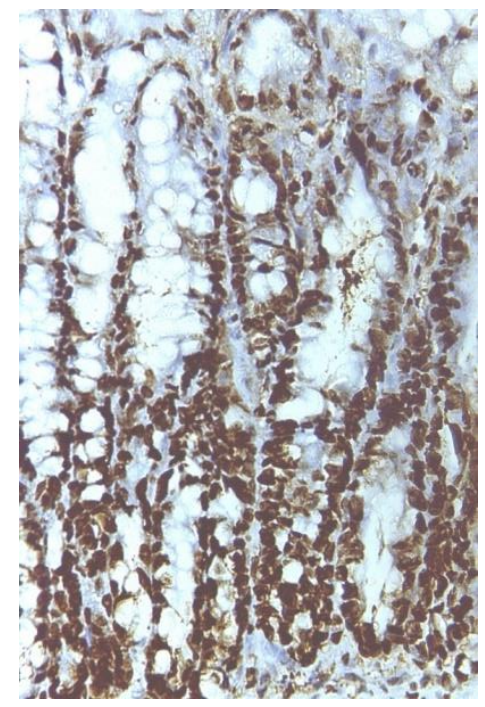

Fig. (16): A Photomicrograph of a section in the rat colon of MSC group (group IV) showing an apparent increase in PCNA immune reaction. (PCNA immunostaining x 400) 


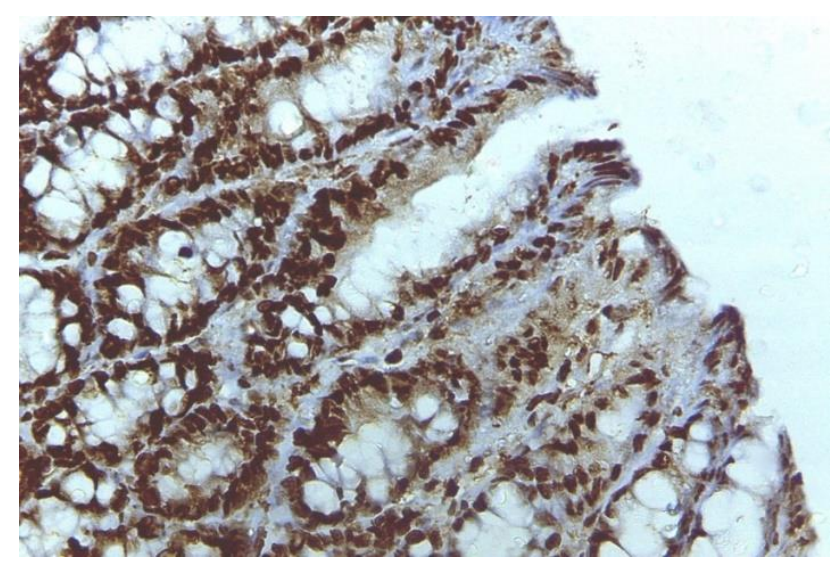

Fig. (17): A Photomicrograph of MSC and vitamin E group (group V) showing an apparent increase in PCNA immune reaction. (PCNA immunostaining x 400)

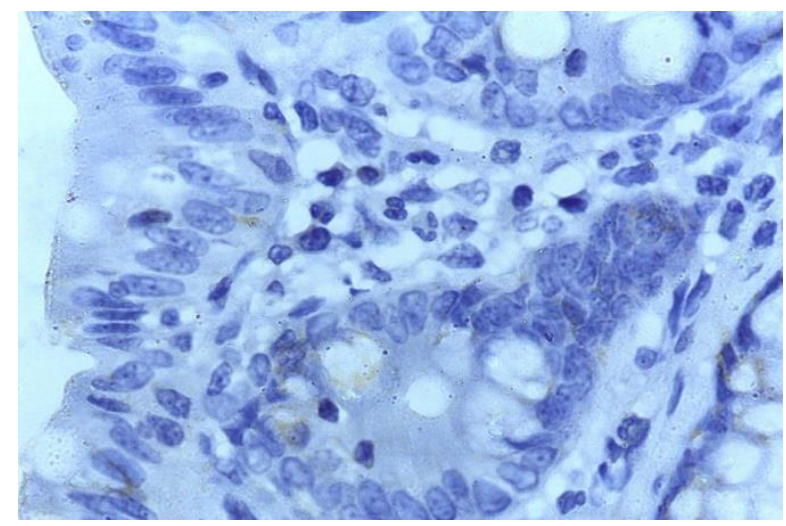

Fig. (18): A Photomicrograph of a section in the rat colon of control group (group I) showing apparent very faint COX2 positive immunoreaction in both columnar epithelial cells and goblet cells. (COX-2 immunostaining $\mathrm{x} 1000$ )

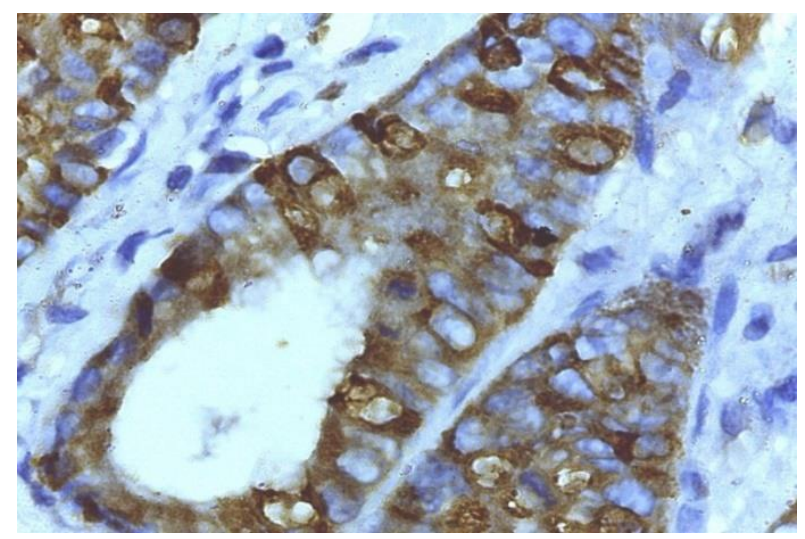

Fig. (19): A Photomicrograph of a section in the rat colon of colitis group (group II) showing colonic glands with strong COX-2 positive immunoreaction. (COX-2 immunostaining $\mathrm{x} 1000$ ) 
Benha medical journal vol. 38, issue 1, 2021

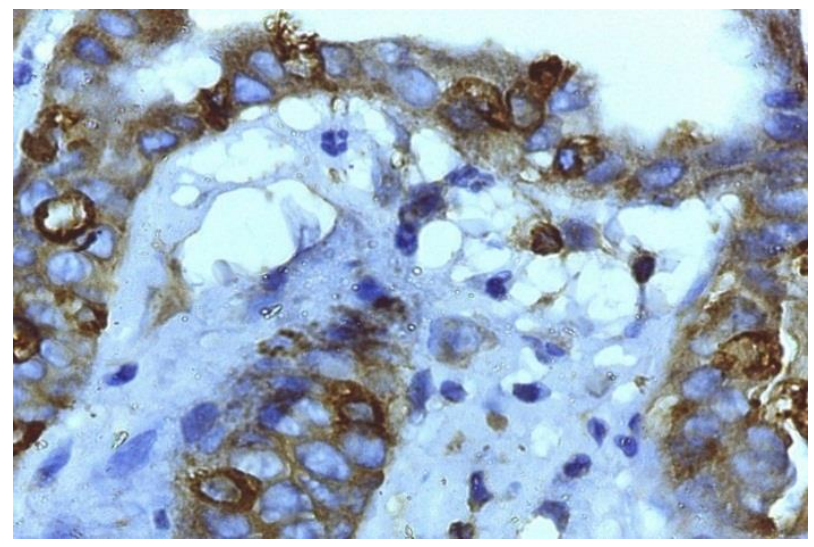

Fig. (20): A Photomicrograph of a section in the rat colon of vitamin E group (group II) showing apparent strong COX2 positive immunoreaction in both columnar epithelial cells and goblet cells. (COX-2 immunostaining $\mathrm{x} 1000$ )

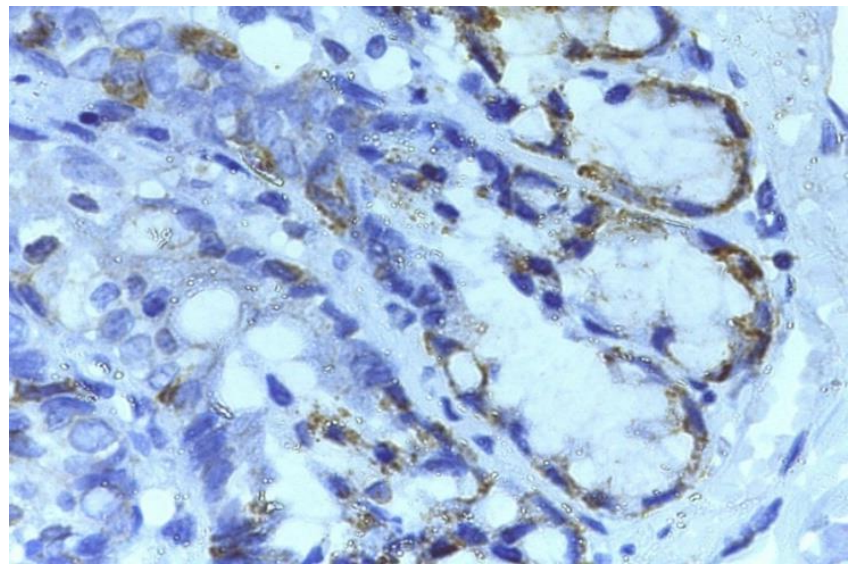

Fig. (21): A Photomicrograph of a section in the rat colon of MSC group (group IV) showing areas of apparent decrease in COX-2 expression in relation to colitis group. (COX-2 immunostaining $\mathrm{x}$ 1000)

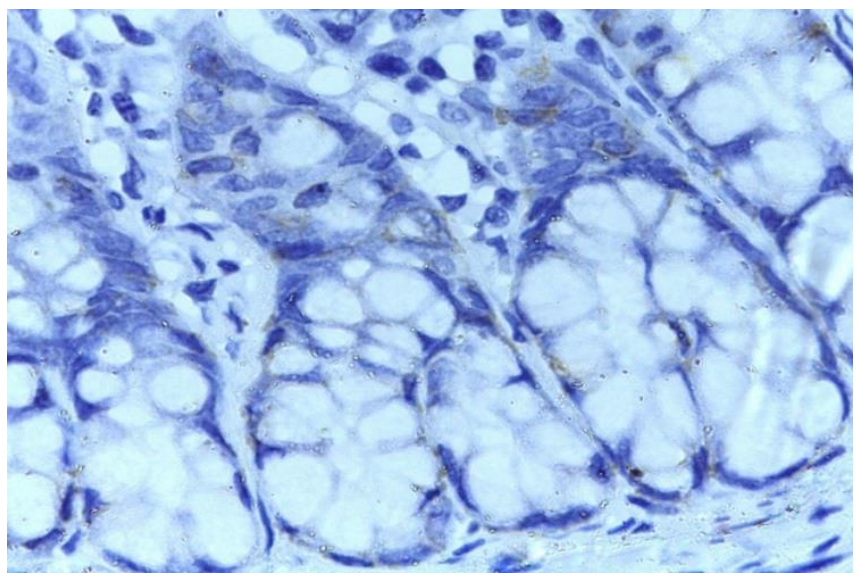

Fig. (22): A Photomicrograph of a section in the rat colon of MSC and vitamin E group (group V) showing apparent weak COX-2 positive immunoreaction in both columnar epithelial cells and goblet cells. (COX-2 immunostaining $\mathrm{x}$ 1000) 


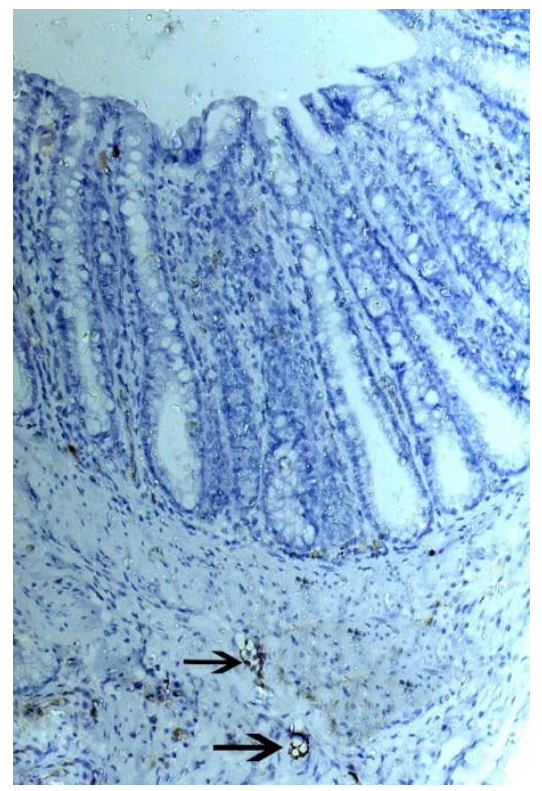

Fig. (23): A Photomicrograph of a section in the rat colon of control group (group I) showing apparent few positive brownish immunostained blood vessels to factor VIII (arrow). (factor VIII immunostaining x 200)

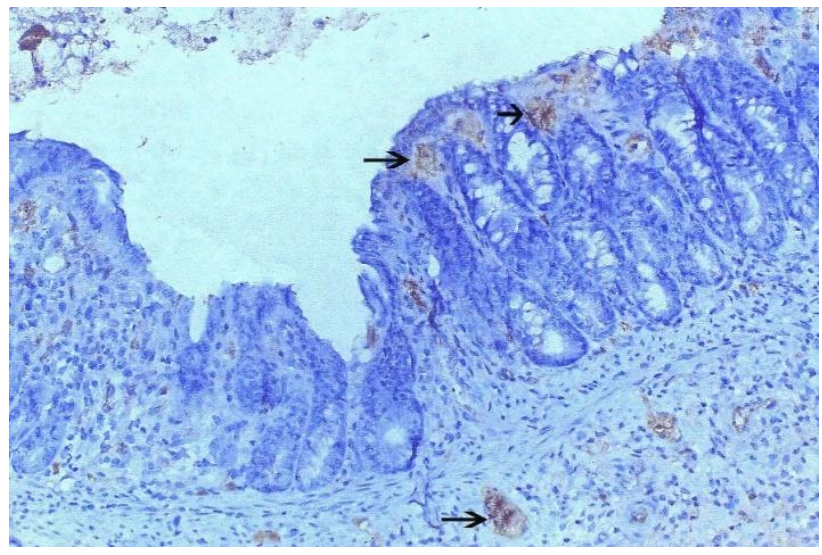

Fig. (24): A Photomicrograph of a section in the rat colon of colitis group (group II) showing increase in number of blood vessels with +ve immunostaining to factor VIII in colon sections, together with dilated congested blood vessels (arrow). (factor VIII immunostaining x 200)

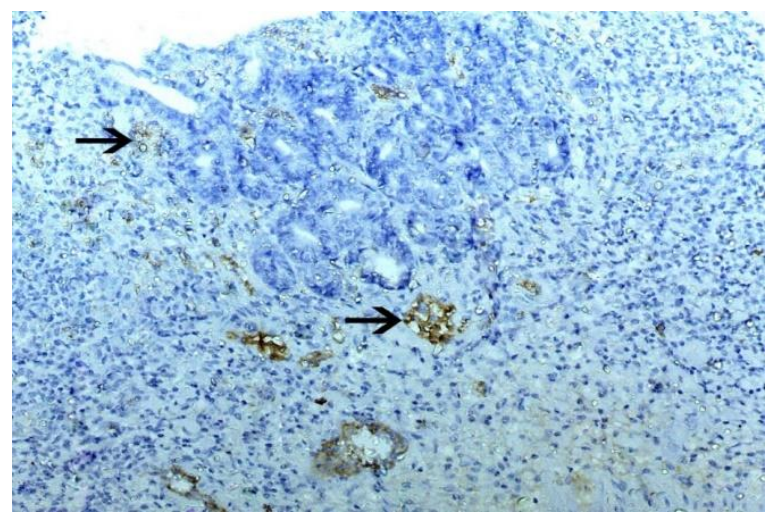

Fig. (25): A Photomicrograph of a section in the rat colon of vitamin E group (group III) showing apparent increase in number of blood vessels with +ve immunostaining of factor VIII. (arrow). (factor VIII immunostaining x 200) 
Benha medical journal vol. 38, issue 1, 2021

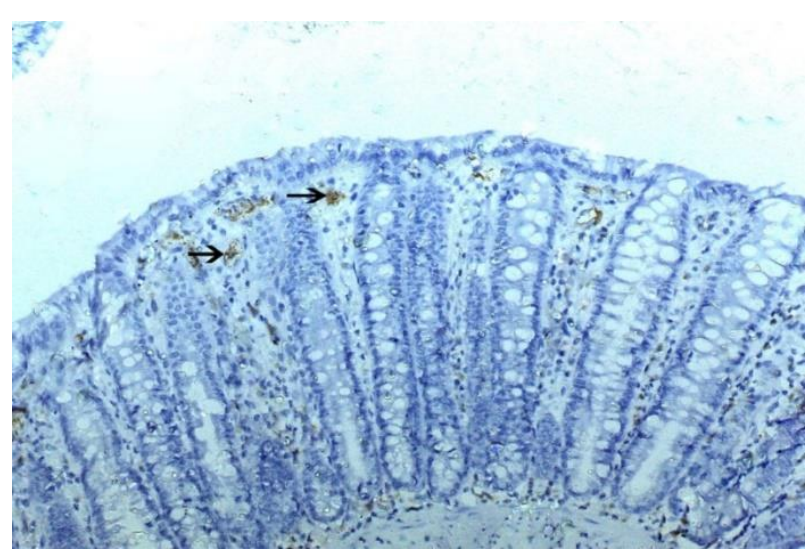

Fig. (26): A Photomicrograph of a section in the rat colon of MSC group (group IV) showing less +ve immunostained blood vessels to factor VIII in relation to colitis group (arrow). (factor VIII immunostaining x 200)

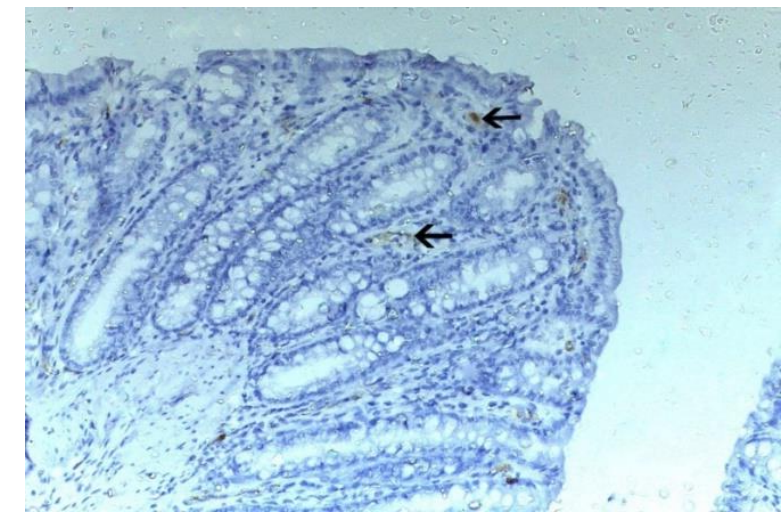

Fig. (27): A Photomicrograph of a section in the rat colon of MSC and vitamin E group (group V) showing a few +ve brownish immunostained blood vessels to factor VIII in relation to colitis group (arrow). (factor VIII immunostaining $\mathrm{x}$ 200)

Table (1): The mean number of goblet cells in PAS stained sections in different studied groups.

\begin{tabular}{llll}
\hline Groups & Mean & SD & Sig. \\
\hline Group I & $\mathbf{6 1 . 2 0 0 0}$ & $\mathbf{5 . 5 9 2 8 5}$ & II, III \\
Group II & $\mathbf{1 2 . 6 6 0 0}$ & $\mathbf{2 . 1 0 6 7 1}$ & I, IV, V \\
Group III & $\mathbf{1 7 . 8 5 5 0}$ & $\mathbf{2 . 8 5 0 0 4}$ & I, IV, V \\
Group IV & $\mathbf{5 8 . 1 3 8 0}$ & $\mathbf{4 . 2 6 4 0 7}$ & II, III \\
Group V & $\mathbf{6 0 . 4 4 8 0}$ & $\mathbf{5 . 5 3 6 1 3}$ & II, III \\
\hline SD = standard deviation & & & \\
Sig. = significant & & &
\end{tabular}




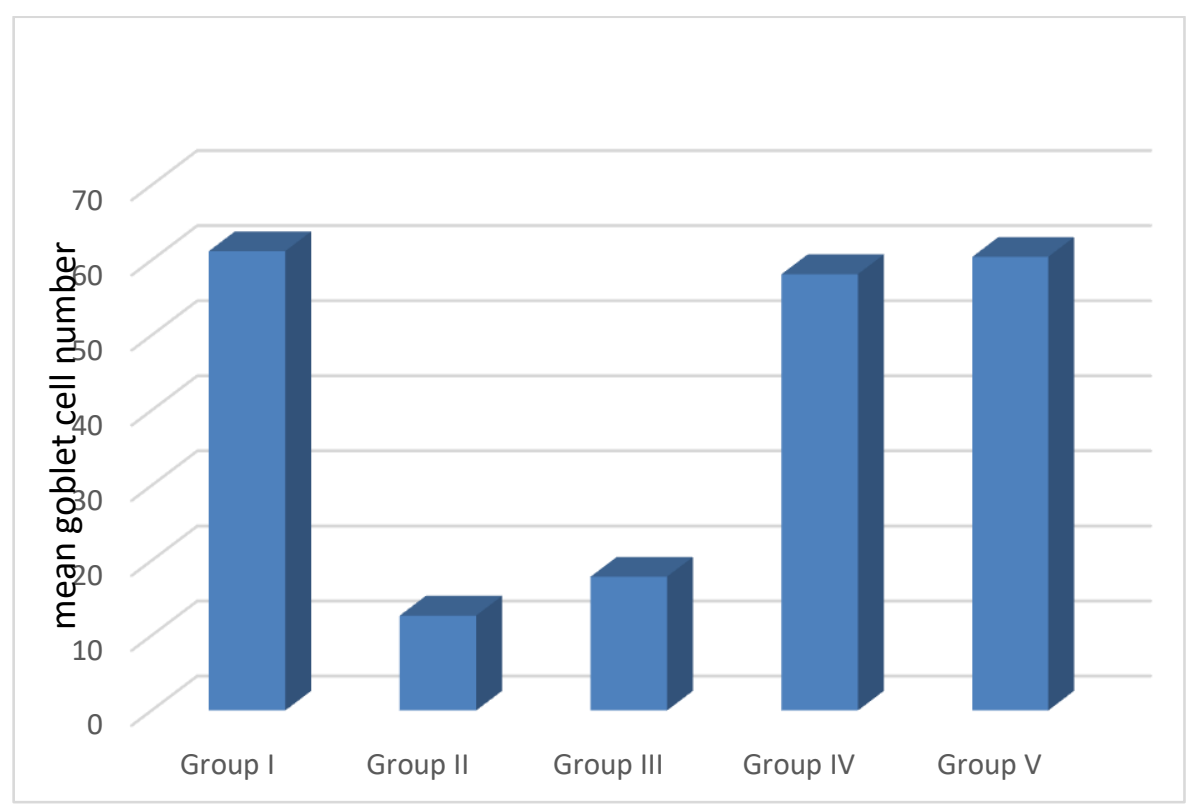

Histogram (1): The mean number of goblet cells in PAS stained sections in different studied groups.

Table (2): The mean number of positive immunoreactive cells for PCNA in different studied groups.

\begin{tabular}{llll}
\hline Groups & Mean & SD & Sig. \\
\hline Group I & 67.20 & 5.116 & II, IV, V \\
Group II & 52.60 & 8.540 & I, IV, V \\
Group III & 53.40 & 8.922 & I, IV, V \\
Group IV & 125.80 & 11.193 & I, II, III \\
Group V & 136.10 & 12.810 & I, II, III \\
\hline
\end{tabular}

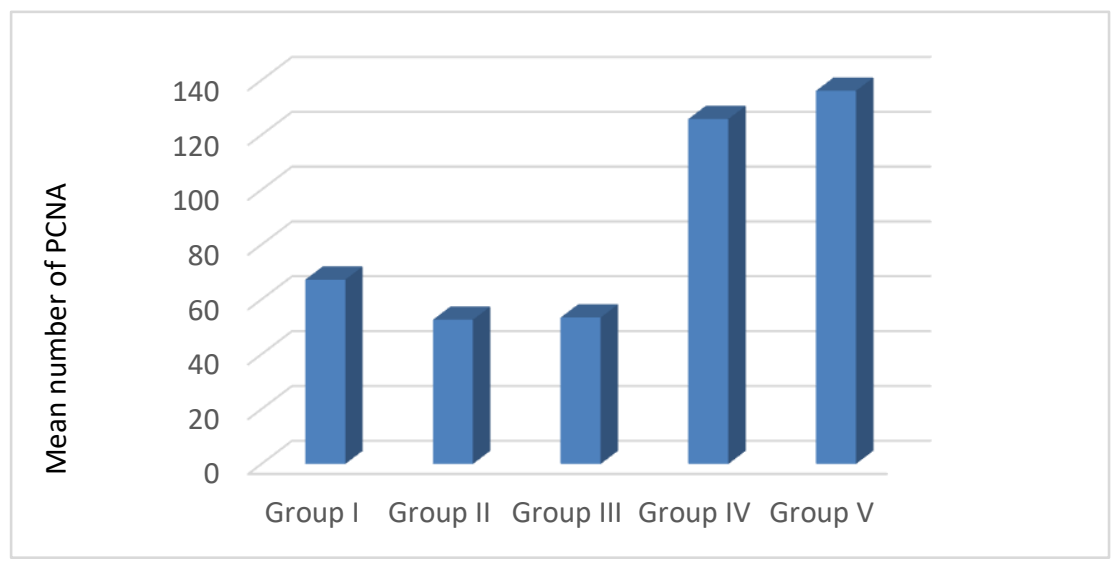

Histogram (2): The mean number of positive immunoreactive cells for PCNA in different studied groups. 
Benha medical journal vol. 38, issue 1, 2021

Table (3): The mean area\% of positive immunoreactivity for COX2 in different studied groups.

\begin{tabular}{llll}
\hline Groups & Mean & SD & Sig. \\
\hline Group I & 7.7880 & 1.05987 & II, III \\
Group II & 37.2460 & 3.66776 & I, IV, V \\
Group III & 35.8020 & 3.97675 & I, IV, V \\
Group IV & 10.1140 & .78469 & II, III \\
Group V & 8.7140 & .86754 & II, III \\
\hline
\end{tabular}

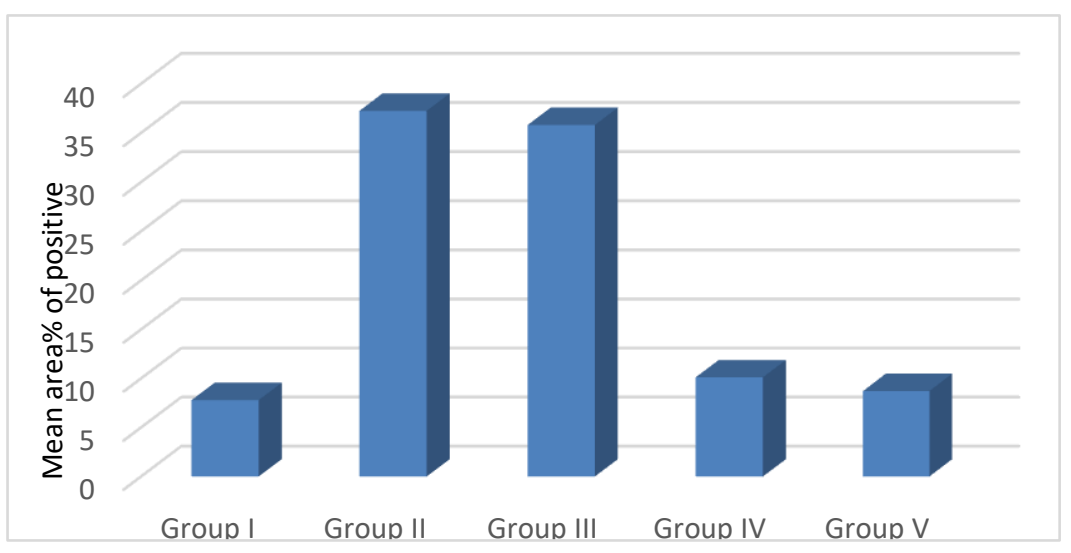

Histogram (V-3): The mean area\% of positive immunoreactivity for COX2in different studied groups.

Table (4): The mean vascular density for factor VIII positive endothelial cells in different studied groups.

\begin{tabular}{llll}
\hline Groups & Mean & SD & Sig. \\
\hline Group I & 6.0000 & 1.00000 & II, III \\
Group II & 19.0000 & 1.00000 & I, IV, V \\
Group III & 18.3333 & 1.15470 & I, IV, V \\
Group IV & 7.6667 & 1.52753 & II, III \\
Group V & 6.6667 & 1.52753 & II, III \\
\hline
\end{tabular}

[

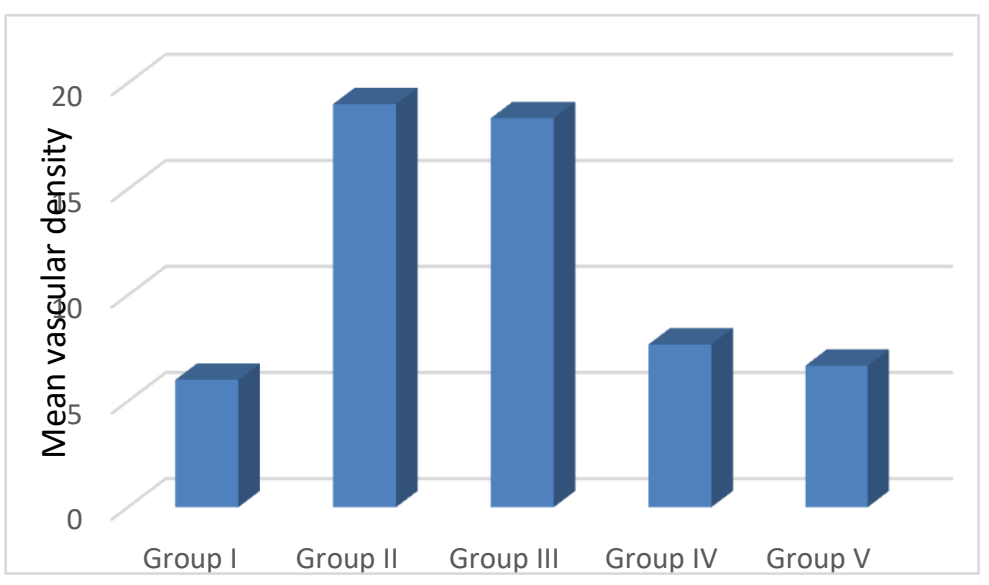

Histogram (4): The mean vascular density for factor VIII positive endothelial cells in different studied groups. 


\section{Discussion}

$\mathrm{UC}$ is a chronic immune-mediated disease, characterized by being chronic relapsing non-transmural and restricted to the colon. It is of multifactorial etiology influenced by genetic and environmental factors. However, the pathogenesis of IBD remains poorly understood (28). Although several experimental treatments, including aminosalicylic acids, corticosteroids, thiopurines and anti-tumor necrosis factor (TNF)- $\alpha$ treatment, have been developed for patients with UC, there is still no widely accepted effective treatment for UC. Clearly, new therapies are needed to treat this condition (30). Acetic acid was used in the present study to induce UC as it is a widely used experimental model for studying UC $(16,30,31)$.

In the present study, the UC group (group II) showed areas of ulceration of surface columnar epithelial lining, disturbed crypt architecture with reduced intensity of PASpositive reaction for goblet cells and dilated congested blood capillaries with extravasated RBCs. The lamina propria showed infiltration by many inflammatory cells. Marked reduction in PCNA immunoreactive cells, marked increase in both $\mathrm{COX} 2$ immunoreactivity expression and number of blood vessels with +ve immunostaining to factor VIII. These 
indicates significant decrease in secretory activity of the colon mucosa reducing its protective function. Furthermore, the defective differentiation of goblet cells from intestinal stem cells leads to goblet cell depletion and mucin induction deficiency in active UC. The defective mucus barrier in UC, may result in a collapse of the physical barrier, which enables the luminal microbes to invade the mucosa and trigger inflammation (39).

The weak PCNA expression was supported by a study (40) that reported a decreased proliferative index in dextran sulfate sodium (DSS) -induced UC in mice. PCNA positive cells are in the $\mathrm{S}$ phase of the cell cycle, so this antigen may be used as a marker for proliferating cells. In the colon, the number of crypt cells is strictly regulated, and the balance between cell proliferation and cell death is required to maintain homeostasis. However, cell proliferation in experimental colitis models is controversial (41). The increased COX-2 expression in UC group was confirmed by the study (42) that stated that increased COX-2, a cyclooxygenase enzyme involved in the conversion of arachidonic acid to prostaglandins (PGs), accelerates damage of genetic material in IBD through increased production of malondialdehyde, a by-product of COX- mediated PG synthesis and lipid peroxidation.

The increased number of blood vessels seen with factor VIII immunostaining in UC group could be correlated with the disease activity and expression of vascular endothelial growth factor (VEGF), as angiogenesis is an important part of the pathogenesis of IBD (43).

Vitamin E group (Group III) revealed histological changes in colonic mucosa nearly similar to that of the UC group as longer time might be needed for vitamin $\mathrm{E}$ therapy to regenerate the lost cells in AAinduced UC. There was decrease in PASpositive reaction for goblet cells and number of PCNA immunoreactive cells, A significant increase in both the COX-2 expression and number of blood vessels with +ve immunostaining to factor VIII versus the control group. These results were in agreement with those of some authors (44), who reported that supplementation of vitamin $\mathrm{E}$ alone was effective in reducing the levels of malondialdehyde and Protein carbonyl (which are used in assessment of oxidative stress) but did not cause any improvement in histopathological colonic lesions. Moreover, vitamin E exerted protective effects on moderate but not severe colitis and its promoted tumorigenesis, this indicates that 
inflammation severity should be considered in evaluating effectiveness of vitamin $\mathrm{E}$ (45).

Another study reported that vitamin E protected rats against TNBS-induced UC by reducing tissue damage, lipid peroxidation, and proinflammatory cytokines but on the other hand, neutrophil recruitment was not affected by vitamin $\mathrm{E}$, therefore the necessity of defined studies using combinations of micronutrients that have the potential of ameliorating not only one but various classical IBD features such as oxidative stress, production of proinflammatory cytokines, neutrophil infiltration, and epithelial dysfunction (45)

In the current study, in group IV (BM-MSC group), the morphological changes in colonic mucosa observed in the previous two groups exhibited improvement in the form of apparently normal intact surface columnar cells. Some mucosal crypts were apparently intact and were spaced by little inflammatory cell infiltration. The mucosa and the crypts were lined by numerous mucin secreting cells confirmed with a significant increase in the mean number of PAS +ve goblet cells compared to UC group. The immunohistochemical studies revealed significant increase in the number of PCNA immunoreactive cells, significant decrease in both the COX-2 expression and number of blood vessels with +ve immunostaining to factor VIII versus UC group .

In agreement with these findings some authors [46] reported that have shown that transplanted MSCs accumulate in inflamed regions of the colon and contribute to tissue repair by a differentiation into intestinal epithelial cells and matrix cells, so it could be an effective method for colon repair. However, the strong immunosuppressive effect on IBD was largely owing to paracrine function because of the poor transitory persistence and survival ability of MSCs. MSCs exert a paracrine function by secreting immunosuppressive agents which inhibit granulocyte infiltration such as $\mathrm{T}$ cells, B cells, NK cells, and antigen presenting cells to exert immunosuppressive function through different pathways $(47,48)$. The increased PCNA immunoreactive cells seen in this study could be attributed to the ability of stem cells to divide and replace the damaged epithelial cells. as this reflects an intense driving force of epithelial cell proliferation (49).

Comparing Group V (BM-MSC and vitamin E group) with the previous groups, there was more pronounced improvement with a histological picture nearly similar to that of the control group. The crypts were 
lined mainly by goblet cells and a strong PAS +ve reaction, similar to control group, that was confirmed statistically by the significant increase in mean number of goblet cells and PCNA immunoreactive cells in comparison to UC group. There was a significant decrease in the COX-2 expression and number of blood vessels with +ve immunostaining to factor VIII when compared to UC group .

Recent studies [50-51] reported that antioxidants like vitamin $\mathrm{C}$ could induce functional MSC sheets, and therefore improve tissue regeneration. They claimed this because of the ability of antioxidants to delay premature cell aging and inactivity, in addition to inhibiting and repairing oxidative DNA damage, and preventing low-density lipoprotein oxidation by scavenging the reactive free radicals/oxidative species generated by various biological processes. lee et al. (52) revealed that combination of antioxidant and stem cells therapy was more effective and produced an additive effect than using each single agent alone. Lower efficacy of stem cell therapy alone could be attributed to the unsuitable pathological microenvironment at the injured sites as oxidative stress, inflammation which could lead to cellular apoptosis. Therefore, using antioxidants result in an increase in stem cell survival and efficacy after transplantation (53)

\section{Conclusion}

In conclusion, the current study highlights evidences for the promising therapeutic effect of systemic infusion of BM- MSCs on acetic acid induced UC in rats through their anti-inflammatory effects and regenerative capacity, so using bone marrow-derived MSCs to treat IBD is possible. Added to that, the combination of the antioxidant vitamin E and BM- MSCs was more effective and produced an additive effect than using bone marrow derived MSCs alone.

\section{Reference}

1. Si, X. Y., Merlin, D. and Xiao, B. (2016): Recent advances in orally administered cellspecific nanotherapeutics for inflammatory bowel disease, World Journal of Gastroenterology, 22(34): 7718-7726.

2. Cha, H., Lee S., Hwan Kim S., Kim H., Lee D. S., Lee H. S., Lee J. H. and Park J. (2017): Increased susceptibility of IDH2-deficient mice to dextran sodium sulfate-induced colitis. Redox Biology, 13: 32-38.

3. Kumar V. L., Pandeya A., Vermaa S. and Dasb P. (2019): Protection afforded by methanol extract of Calotropis procera latex in experimental model of colitis is mediated through inhibition of oxidative stress and proinflammatory signaling, Biomedicine and Pharmacotherapy, 109:1602-1609. 
4. Pawar P., Gilda S., Sharma S., Jagtap S., Paradkar A., Mahadik K., Ranjekar P. and Harsulkar A. (2011): Rectal gel application of Withania somnifera root extract expounds antiinflammatory and muco-restorative activity in TNBS-induced inflammatory bowel disease, BMC Complement. Altern. Med. 11:1-34,

5. Bezerra G. B., De Menezes de Souza L., Dos Santos A.S., De Almeida G.K, Souza M.T., Santos S.L., Aparecido Camargo E., Dos Santos Lima B., De Souza Araujo A.A, Cardoso J.C., Gomes S.V., Gomes M.Z. and De Albuquerque R.L.J. (2017): Hydroalcoholic extract of Brazilian red propolis exerts protective effects on acetic acid-induced ulcerative colitis in a rodent model, Biomed. Pharmacother., 85: 687696.

6. El-Akabawy, G. and El-Sherif, N. M. (2019): Zeaxanthin exerts protective effects on acetic acid-induced colitis in rats via modulation of pro-inflammatory cytokines and oxidative stress, Biomedicine and Pharmacotherapy. Elsevier, 111: 841-851.

7. (7) Cho Y.B., Kim M.S., Kang M.J., Shin H.J., Kim S-H., Kim H.C., Yun S.H., Lee W.Y. and Chun H-K. (2010): Immunomodulatory Effects of Mesenchymal Stem Cells in a Murine Model of TNBS-Induced Colitis. J. Korean Surg. Soc.; 79: pp.317-325.

8. Klontzas, M. E., Drissi, H., \& Mantalaris, A. (2019): The Use of Alginate Hydrogels for the Culture of Mesenchymal Stem Cells (MSCs): In Vitro and In Vivo Paradigms. In Alginates. IntechOpen.

9. Hwang ES, Ok JS and Song S. (2016): Chemical and physical approaches to extend the replicative and differentiation potential of stem cells. Stem Cell Rev.; 12:315-326.
10. Khatiwala, R. and Cai, C. (2016): Strategies to Enhance the Effectiveness of Adult Stem Cell Therapy for Ischemic Heart Diseases Affecting the Elderly Patients, Stem Cell Rev., 12(2): $214-223$.

11. Kim, H., Yun, J. and Kwon, S.M. (2016): Therapeutic Strategies for Oxidative StressRelated Cardiovascular Diseases: Removal of Excess Reactive Oxygen Species in Adult Stem Cells, Oxidative Medicine and Cellular Longevity, 1-11.

12. Azzi A. (2018): Review, Many tocopherols, one vitamin E, Molecular Aspects of Medicine, 61: 92-103.

13. Wallert M., Schmolz L., Galli F., Birringer M., and Lorkowski S., (2014): "Regulatory metabolites of vitamin $\mathrm{E}$ and their putative relevance for atherogenesis," Redox Biology, 2(1):495-503.

14. Bitiren, M., Karakilcik, A. Z., Zerin, M., Ozardalı, I., Selek, S., Nazlıgül, Y., .. \& Uzunkoy, A. (2010). Protective effects of selenium and vitamin $\mathrm{E}$ combination on experimental colitis in blood plasma and colon of rats. Biological trace element research, 136(1), 87-95.

15. Bitiren, M., Karakilcik, A. Z., Zerin, M., OzardalI, I., Selek, S. and NazlIgül, Y. (2010): Protective effects of selenium and vitamin e combination on experimental colitis in blood plasma and colon of rats. Biological Trace Element Research, 136(1): 87-95.

16. Hagar H.H., El Medany A., El Eter E. and Arafa M. (2007): Ameliorative effect of pyrolidinedithiocarbamate on acetic acidinduced colitis in rats. European Journal of Pharmacology; 554: pp.69-77.

17. Dodda, D., Chhajed, R., \& Mishra, J. (2014): Protective effect of quercetin against acetic acid 
Benha medical journal vol. 38, issue 1, 2021

induced inflammatory bowel disease (IBD) like symptoms in rats: Possible morphological and biochemical alterations. Pharmacological Reports, 66(1), 169-173.

18. Abdel Aziz M.T., Atta H., Mahfouz S., Fouad H.H., Roshdy N.K., Ahmed H.H., Rashed L.A., Sabry D., Hassouna A.A. and Hasan N.M. (2007): Therapeutic potential of bone marrowderived mesenchymal stem cells on experimental liver cirrhosis. Clin. Biochem.; 40: pp.893-899.

19. Feng S.W., Yao X.L., Li Z., Liu T.Y., Huang W. and Zhang C. (2005): In vitro bromodeoxyuridine labeling of rat bone marrow-derived mesenchymal stem cells. Di Yi Jun Yi Da Xue Xue Bao; 25: pp.184-186.

20. Aziz, M. T. A., Wassef, M. A. A., Ahmed, H. H., Rashed, L., Mahfouz, S., Aly, M. I., and Abdelaziz, M. (2014): The role of bone marrow derived-mesenchymal stem cells in attenuation of kidney function in rats with diabetic nephropathy. Diabetology \& metabolic syndrome, 6(1), 34 .

21. Uraz, S., Tahan, G., Aytekin, H., and Tahan, V. (2013): N-acetylcysteine expresses powerful anti-inflammatory and antioxidant activities resulting in complete improvement of acetic acid-induced colitis in rats. Scandinavian journal of clinical and laboratory investigation, 73(1), 61-66.

22. Suvarna, K. S., Layton, C., \& Bancroft, J. D. (2018): Bancroft's Theory and Practice of Histological Techniques E-Book. Elsevier Health Sciences, Churchill Livingstone, pp.177183.

23. Bancroft J. D and Layton C. (2013): The Hematoxylin and eosin. Theory Practice of histological techniques. 7th ed. Ch. 10 and 11.
Philadelphia: Churchill Livingstone of El Sevier, pp. 179-220

24. Bancroft J.D. and Gamble M.N. (2002): Mucins in: Theory Practice of Histological Technique, 5th ed, Churchill Livingstone, pp.177-183.

25. Buchwalow, I.B. and Bocker, W. (2010): Immunohistochemistry Basics and methods, Springer Heidelberg, Dordecht, London, New York.

26. Suvarna, K. S., Layton, C., \& Bancroft, J. D. (2018): Bancroft's Theory and Practice of Histological Techniques E-Book. Elsevier Health Sciences, Churchill Livingstone, pp.177183.

27. Emsley, R., Dunn, G., and White, I. R. (2010): Mediation and moderation of treatment effects in randomised controlled trials of complex interventions. Statistical Methods in Medical Research, 19(3): 237-270.

28. Iskandar H.N., Dhere T. and Farraye F.A. (2015): Ulcerative Colitis: Update on Medical Management. Curr. Gastroenterol. Rep., 17(11):44-56.

29. Chen P, Bakke D, Kolodziej L, Lodolce J, Weber CR, Boone DL, Toback FG (2015): Antrum mucosal protein-18 peptide targets tight junctions to protect and heal barrier structure and function in models of inflammatory bowel disease. Inflamm Bowel Dis; 21:2393-2402.

30. Bezerra G. B., De Menezes de Souza L., Dos Santos A.S., De Almeida G.K, Souza M.T., Santos S.L., Aparecido Camargo E., Dos Santos Lima B., De Souza Araujo A.A, Cardoso J.C., Gomes S.V., Gomes M.Z. and De Albuquerque R.L.J. (2017): Hydroalcoholic extract of Brazilian red propolis exerts protective effects on acetic acid-induced ulcerative colitis in a rodent model, Biomed. Pharmacother., 85: 687696. 
31. El-Akabawy, G. and El-Sherif, N. M. (2019): Zeaxanthin exerts protective effects on acetic acid-induced colitis in rats via modulation of pro-inflammatory cytokines and oxidative stress, Biomedicine and Pharmacotherapy. Elsevier, 111: 841-851.

32. Soliman, N. B. E., Kalleny, N. K., and Abd El Samad, A. A. (2010): Effect of Omega-3 versus Omega-6 fatty acids on induced ulcerative colitis in male albino rat. light and electron microscopic study. Egyptian Journal of Histology, 33(4), 620-634.

33. Dileep, R., Usharani, M., Gopu, B., Reddy, A. G., Kumar, M. V., Venkat Satish Kumar, C. S. and Madhuri, D. (2016): Ameliorative effect of ginger extract in acetic acid induced ulcerative colitis in rats. Asian Journal of Animal and Veterinary Advances, 11(2): 130-136.

34. Rana, S.V., S. Sharma, K.K. Prasad, S.K. Sinha and K. Singh, (2014): Role of oxidative stress and antioxidant defence in ulcerative colitis patients from North India. Indian J. Med. Res., 139: 568-571.

35. Soliman, N. A., Keshk, W. A., Rizk, F. H., \& Ibrahim, M. A. (2019): The possible ameliorative effect of simvastatin versus sulfasalazine on acetic acid induced ulcerative colitis in adult rats. Chemico-Biological Interactions, 298: 57-65.

36. Balaha, M., Kandeel, S., \& Elwan, W. (2016): Garlic oil inhibits dextran sodium sulfateinduced ulcerative colitis in rats. Life sciences, $146,40-51$.

37. Chaudhary, G., Mahajan, U. B., Goyal, S. N., Ojha, S., Patil, C. R., \& Subramanya, S. B. (2017): Protective effect of Lagerstroemia speciosa against dextran sulfate sodium induced ulcerative colitis in C57BL/6 mice. American journal of translational research, 9(4), 1792.
38. Dorofeyev, A. E., Vasilenko, I. V, Rassokhina, O. A., \& Kondratiuk, R. B. (2013): Mucosal barrier in ulcerative colitis and Crohn's disease. Gastroenterology Research and Practice, 1-9 e431231

39. Gersemann, M., Stange, E. F. and Wehkamp, J. (2011): From intestinal stem cells to inflammatory bowel diseases, World Journal of Gastroenterology, 17(27): 3198-3203.

40. Araki Y., Mukaisyo K., Sugihara H., Fujiyama Y., and Hattori T. (2010): Increased apoptosis and decreased proliferation of colonic epithelium in dextran sulfate sodium-induced colitis in mice, Oncology Reports, 24(4):869874.

41. Vasconcelos P. C. D. P., Seito L. N., Di Stasi L. C., Akiko Hiruma-Lima C. and Pellizzon, C. H. (2012): Epicatechin used in the treatment of intestinal inflammatory disease: An analysis by experimental models. Evidence-Based Complementary and Alternative Medicine.

42. El-Akabawy, G. and El-Sherif, N. M. (2019): Zeaxanthin exerts protective effects on acetic acid-induced colitis in rats via modulation of pro-inflammatory cytokines and oxidative stress, Biomedicine and Pharmacotherapy. Elsevier, 111: 841-851.

43. Alkim C., Alkim H., Koksal A. R., Boga S. and Sen I. (2015): Angiogenesis in Inflammatory Bowel Disease, International Journal of Inflammation, 1-10.

44. Olgac, V., Barbaros, U., Tam, B., Erbil, Y., Mutlu-Turkoglu, U., Ademoglu, E., and İlhan, E. (2004): Do Vitamin E and Selenium Have Beneficial Effects on Trinitrobenzenesulfonic Acid-Induced Experimental Colitis. Digestive Diseases and Sciences, 49(1): 102-108.

45. Jiang Q., Jiang Z., Hall Y. J. Jang, Y., Snyder, P. W., Bain, C. and Moreland M. (2013): 
“Gamma-tocopherol attenuates moderate but not severe colitis and suppresses moderate colitis promoted colon tumorigenesis in mice," Free Radical Biology \&Medicine, 65:1069-1077.

46. Yemm A., Adams D., and Kalia N. (2015): "Targeting the delivery of systemically administered haematopoietic stem/progenitor cells to the inflamed colon using hydrogen peroxide and platelet microparticle pretreatment strategies," Stem Cell Research, 15(3):569-580.

47. Zuo D., Tang Q., Fan H. Shou, Z., Liu, X., Cao, D. and Zou, Z. (2015): "Modulation of nuclear factor- $\kappa \mathrm{B}$ - mediated pro-inflammatory response is associated with exogenous administration of bone marrow-derived mesenchymal stem cells for treatment of experimental colitis," Molecular Medicine Reports, 11:(4)2741-2748.

48. Wang, Z., Li, S., Cao, Y., Tian, X., Zeng, R., Liao, D.F., Cao, D., (2016): Oxidative stress and carbonyl lesions in ulcerative colitis and associated colorectal cancer. Oxid. Med. Cell. Longev. 2016.

49. Tanaka H., Arimura Y., Yabana T., Goto A., Hosokawa M.., Nagaishi K., Yamashita K., Yamamoto H., Sasaki Y., Fujimiya M., Imai K. and Shinomura Y., (2011): Myogenic lineage differentiated mesenchymal stem cells enhance recovery from dextran sulfate sodium-induced colitis in the rat, J. Gastroenterol.; 46:143-152

50. Wei F., Qu C., Song T., Ding G., Fan Z., Liu D., Liu Y., Zhang C., Shi S. and S. Wang (2012): Vitamin C treatment promotes mesenchymal stem cell sheet formation and tissue regeneration by elevating telomerase activity, J. Cell. Physiol. 227: $3216-3224$

51. Yang M, Xiao J and Liu Y. (2015): Endogenous antioxidant level of stem cell is important for the transplantation efficacy. Inflamm. Cell Signal., 2(4).

52. Lee, W.Y.; Wei, H.J.; Lin, W.W.; Yeh, Y.C.; Hwang, S.M. and Wang, J.J. (2011): "Enhancement of cell retention and functional benefits in myocardial infarction using human amniotic-fluid stem-cell bodies enriched with endogenous ECM". Biomaterials. 32 (24): 5558-5567.

53. Ok, J. S., Song, S. B., and Hwang, E. S. (2018): Enhancement of Replication and Differentiation Potential of Human Bone Marrow Stem Cells by Nicotinamide Treatment. International journal of stem cells, 11(1):13-25.

To cite this article: Omayma K. Helal, Hala G. Metwaly, Maha M. Abo Gazia, Rania El Desoki, Naira El Ashmouny. The possible therapeutic Effect of Mesenchymal Stem Cells and Vitamin E on Experimentally Induced Ulcerative Colitis in Adult Male Albino Rats: Histological and immunohistochemical study. BMFJ 2021;38(1): 294-321. DOI: 10.21608/bmfj.2021.24068.1215 